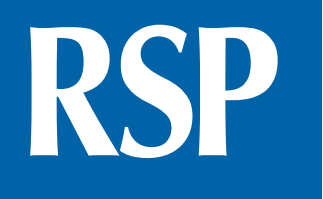

http://www.rsp.fsp.usp.br/
Revista de Saúde Pública

\title{
Adaptação transcultural do Adverse Childhood Experiences International Questionnaire
}

\author{
Flávia Garcia Pereira' iD, Maria Carmen Viana ${ }^{1,11}$ \\ ' Universidade Federal do Espírito Santo. Programa de Pós-Graduação em Saúde Coletiva. Vitória, ES, Brasil \\ " Universidade Federal do Espírito Santo. Departamento de Medicina Social. Vitória, ES, Brasil
}

\section{RESUMO}

OBJETIVO: Traduzir, adaptar e validar o conteúdo do Adverse Childhood Experiences International Questionnaire para uma versão em português, vigente no Brasil, nomeada como Questionário Internacional de Experiências Adversas na Infância.

MÉTODOS: Trata-se de um estudo metodológico de adaptação transcultural de instrumentos de avaliação, em que são apresentados os resultados da equivalência semântica entre o instrumento original e a versão adaptada. A equivalência semântica do instrumento envolveu as seguintes etapas: 1) duas traduções e uma síntese das traduções; 2) duas retraduções; 3) validação de conteúdo realizado por oito profissionais da área da saúde; 4) síntese das retraduções; 5) pré-testes para avaliar a aceitabilidade, a compreensão e o impacto emocional das questões; e, por fim, 6) a elaboração da versão final do instrumento.

RESULTADOS: A versão adaptada demonstrou ser de fácil aplicação e compreensão e obteve boa equivalência semântica quando comparada à original. As propriedades psicométricas do instrumento devem, ainda, ser avaliadas. Limitações e recomendações para a melhoria do instrumento e para a sua utilização são apresentadas.

Correspondência:

Maria Carmen Viana

Departamento de Medicina Social, Centro de Ciências da Saúde - UFES Avenida Marechal Campos, 1.468 29047-105 Maruípe, Vitória, ES, Brasil E-mail: mcviana6@gmail.com

Recebido: 10 set 2020

Aprovado: 21 out 2020

Como citar: Pereira FG, Viana MC. Adaptação transcultural do Adverse Childhood Experiences International Questionnaire. Rev Saude Publica. 2021;55:79. https://doi.org/10.11606/s15188787.2021055003140

Copyright: Este é um artigo de acesso aberto distribuído sob os termos da Licença de Atribuição Creative Commons, que permite uso irrestrito, distribuição e reprodução em qualquer meio, desde que o autor e a fonte originais sejam creditados.
CONCLUSÃO: O processo de adaptação transcultural do Adverse Childhood Experiences International Questionnaire proporcionou uma versão adaptada para o português vigente no Brasil.

DESCRITORES: Experiências Adversas da Infância. Inquéritos e Questionários. Traduções. Adultos Sobreviventes de Eventos Adversos na Infância. Comparação Transcultural. 


\section{INTRODUÇÃO}

Embora a história e a documentação acerca da ocorrência de maus-tratos infantis não sejam recentes ${ }^{1,2}$, o estudo sistemático das experiências adversas na infância (EAI) tornou-se objeto de interesse da comunidade científica a partir da década de 1990, após a publicação dos resultados do Adverse Childhood Experiences (ACE) Study ${ }^{3,4}$.

O ACE Study, realizado em San Diego e conduzido pelo Departamento de Medicina Preventiva da Kaiser Permanente em parceria com o Centro de Controle e Prevenção de Doenças dos Estados Unidos (CDC), é considerado um marco na investigação da exposição ao abuso e negligência durante a infância como fator de risco associado a desfechos negativos de saúde e bem-estar ao longo da vida ${ }^{3,4}$. A partir de sua publicação, diversos estudos epidemiológicos foram conduzidos, dando ênfase a uma crescente preocupação mundial sobre as consequências dos maus-tratos infantis, não somente imediatas, mas também a longo prazo ${ }^{5-7}$.

As EAI podem resultar em morbimortalidade decorrente diretamente da violência, embora, com maior frequência, as consequências envolvam danos emocionais, cognitivos e comportamentais que conferem risco aumentado, tanto para o desenvolvimento de doenças crônicas na vida adulta, como para a exposição a comportamentos de risco na adolescência ${ }^{8}$. Nesse sentido, diversos estudos demonstraram associações positivas e dose-dependente entre a exposição às EAI e doença coronariana, diabetes, câncer, doença pulmonar obstrutiva crônica ${ }^{3}$, transtornos mentais ${ }^{9-11}$, síndrome da fadiga crônica ${ }^{12}$, dor crônica $^{13}$, tentativas de suicídio ${ }^{14}$, comportamento sexual de risco ${ }^{15}$, uso mais precoce de álcool, tabaco e outras drogas ${ }^{16,17}$, e mortalidade prematura ${ }^{18,19}$, entre outros. Além disso, desfechos negativos na vida escolar, renda e ocupação têm sido descritos ${ }^{20}$.

A melhor compreensão do papel deletério das EAI pode proporcionar suporte fundamental para o direcionamento e implementação de estratégias de prevenção, intervenção e tratamento adequados, tanto no estabelecimento de políticas públicas de saúde, justiça e cidadania, quanto na sensibilização, aprimoramento da formação e integração dos profissionais envolvidos na redução de maus-tratos na infância e adolescência e suas consequências $^{21}$. Nesse sentido, o desenvolvimento de instrumentos padronizados de avaliação das EAI é fundamental para que medidas confiáveis e válidas melhorem a qualidade da informação.

Nas três últimas décadas, diversos instrumentos para a investigação das EAI foram propostos, abarcando a avaliação de diferentes categorias e contextos ambientais, com insuficiente verificação subsequente de suas propriedades psicométricas ${ }^{22-24}$. Vale ressaltar que, até a elaboração deste artigo, nenhum instrumento desenvolvido no Brasil foi identificado, embora alguns tenham sido adaptados para uso em populações brasileiras ${ }^{25,26} \mathrm{~A}$ grande variedade de instrumentos empregados tem dificultado a comparabilidade dos resultados produzidos, não somente entre contextos sociais diversos como também entre períodos diferentes na mesma população. Nessa perspectiva, a Organização Mundial da Saúde (OMS), em parceria com o CDC, elaborou o Adverse Childhood Experiences International Questionnaire (ACE-IQ), disponibilizando um instrumento padronizado para a avaliação e vigilância internacional das EAI e possibilitando a formulação de programas e políticas de prevenção globais de maus-tratos infantis ${ }^{27,28}$.

O ACE-IQ foi produzido para ser aplicado em adultos ( $\geq 18$ anos), com o intuito de identificar e avaliar a exposição pregressa a 13 categorias diferentes de EAI, incluindo abuso sexual, emocional e físico, negligência emocional e física, violência familiar, uso de álcool/drogas, doença mental ou suicídio no âmbito domiciliar, envolvimento da família com atividades criminais, separação ou divórcio parental, violência comunitária, violência coletiva e bullying ${ }^{27,28}$. É importante destacar que todos os instrumentos de investigação de EAI coletam informações retrospectivas, sujeitas, portanto, a vieses de memória; além disso, o viés de sobrevida deve ser considerado, uma vez que violências mais graves podem levar ao óbito das vítimas. 
A exposição à violência infantil é de grande relevância no campo da saúde pública, pois representa um risco ao pleno desenvolvimento infantil, com amplo impacto na vida adulta, sendo necessário estudar e comparar perfis epidemiológicos das populações afetadas. No Brasil, ainda são escassos os estudos epidemiológicos de EAI, tendo sido usados diferentes instrumentos de avaliação ou questionários não padronizados, o que dificulta a comparabilidade entre os resultados observados e o contraste com estudos internacionais. Assim, considerando-se que existe um instrumento proposto pela OMS com o intuito de estabelecer parâmetros mundiais, é pertinente a realização de uma adaptação transcultural do ACE-IQ para ser utilizada na população brasileira, já que a elaboração e desenvolvimento de novos instrumentos de avaliação é um processo complexo, que envolve diversas etapas para demonstrar propriedades psicométricas satisfatórias ${ }^{29}$.

A adaptação transcultural é um procedimento minucioso que analisa a utilização da linguagem, levando em consideração o contexto cultural e o estilo de vida da população para a qual o instrumento se destina. É necessário garantir as equivalências conceitual e de itens, semântica, operacional e de mensuração entre o instrumento original e o adaptado ao novo idioma ${ }^{30,31}$.

Com o intuito de disponibilizar um instrumento padronizado de avaliação das EAI para ser usado no Brasil, aumentando a comparabilidade com outros estudos e contribuindo para a validação do novo instrumento proposto pela OMS, foi realizada a adaptação transcultural do ACE-IQ. Neste trabalho apresenta-se a equivalência semântica da versão em português do ACE-IQ, nomeada como Questionário Internacional de Experiências Adversas na Infância (EAI-QI).

\section{MÉTODOS}

O processo de adaptação transcultural (Figura 1) utilizado neste estudo foi baseado na metodologia adotada por Reichenheim e Moraes (2007) ${ }^{32}$ e nas recomendações para a adaptação do ACE-IQ disponibilizadas no site da OMS ${ }^{33,34}$. O ACE-IQ foi desenvolvido para ser utilizado tanto em formato autoaplicado como em entrevistas face a face ${ }^{27,28}$. Para o processo de adaptação transcultural, foi utilizado o questionário em forma de entrevista.

O processo de adaptação transcultural foi dividido em duas fases. A primeira fase consistiu na avaliação da equivalência conceitual e de itens, realizada pelos pesquisadores, que resultou numa revisão integrativa dos instrumentos mais utilizados nos últimos 10 $\operatorname{anos}^{26}$. Inicialmente, foram realizadas discussões temáticas informais junto ao Centro de Estudos e Pesquisa em Epidemiologia Psiquiátrica da Universidade Federal do Espírito Santo (Cepep/Ufes), coordenado por MCV, e formado por mestres e doutores na área de saúde coletiva, a fim de discutir e verificar a relevância dos itens do instrumento original para captar as informações sobre as EAI no contexto brasileiro. As discussões foram baseadas nos principais questionários e inquéritos conduzidos no contexto internacional e local, identificados por meio de um estudo de revisão sistemática das publicações disponíveis até $2003^{24}$.

Em seguida, deu-se início à segunda fase da adaptação transcultural que consistiu na avaliação da equivalência semântica. Essa fase foi subdividida em cinco etapas. Inicialmente (Etapa 1), foram obtidas duas traduções (T1 e T2) do instrumento original em inglês para o português, realizadas de forma independente por tradutores cuja língua materna é o português. Um dos tradutores tem formação profissional em medicina e experiência no campo da violência contra a mulher e o outro tem formação em nutrição e experiência profissional no campo de doenças crônicas não transmissíveis. Ainda na Etapa 1, as discrepâncias nas traduções foram identificadas pelos pesquisadores, solicitando-se aos tradutores que chegassem a um consenso, para, em seguida, obter-se uma versão-síntese (S1) do questionário em português (Etapa 1). 
Tradução independente 1 (T1)

Conhecedor da temática e profissional de saúde
Tradução independente 2 (T2)

Não conhecedor da temática e profissional de saúde

Síntese comum (S1)

Consenso entre os dois tradutores e um observador (pesquisador)

Retradução independente 1 (R1)

Tradutor profissional (língua-mãe: inglês)

Retradução independente 2 (R2) Tradutor profissional (língua-mãe: inglês

\section{Comitê de especialistas}

Identificar e encaminhar os problemas de cada uma das atividades pregressas para apreciação dos pesquisadores Avaliar as equivalências semântica, idiomática e conceitual

Pesquisadores

Avaliar as retraduções e elaborar uma versão-síntese (RS1)

Avaliar as considerações realizadas pelo comitê de especialistas

Primeira versão do questionário em português (Q1)

Pré-teste 1

Aplicar questionário e avaliar a compreensão de cada item através de escala verbal numérica

Segunda versão do questionário em português (Q2)

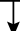

Pré-teste 2

Leitura de cada item pelos participantes e explicação verbal do que foi compreendido

Versão final do questionário em português (EAI-QI)

Figura. Fluxograma do processo de Adaptação Transcultural do Adverse Childhood Experiences International Questionnaire (ACE-IQ).

Na segunda etapa (Etapa 2), S1 foi submetida a duas retraduções (para o inglês) por tradutores independentes cuja língua materna é o inglês, sendo uma delas realizada por uma empresa especializada (R1) e a outra por uma professora da língua inglesa (R2).

Para a realização da terceira etapa (Etapa 3), foram convidados 13 profissionais graduados em diferentes áreas, para compor o comitê de especialistas. O convite foi enviado através de uma carta explicativa, via e-mail, sobre as funções do comitê, contendo, ainda, informações sucintas acerca do questionário ACE-IQ e dos métodos empregados na adaptação transcultural de instrumentos. Oito profissionais aceitaram participar da Etapa 3, sendo seis graduados em medicina, um em psicologia e um em artes, com especialização em antropologia. Os outros sete têm doutorado em diferentes áreas do conhecimento (epidemiologia/saúde coletiva, fisiologia, psiquiatria, psicofarmacologia). A composição de um comitê de especialistas em diferentes áreas do conhecimento tem por objetivo atestar a compreensão ampla do questionário, tendo em vista sua aplicabilidade na avaliação da população geral ${ }^{35}$.

Ao comitê de especialistas foi delegada a avaliação das equivalências semânticas, conceitual e idiomática entre o instrumento original e as duas retraduções obtidas, a fim de verificar a correspondência literal de cada item traduzido e avaliar a correspondência com o significado original, levando em consideração o sentido que algumas palavras assumem no novo contexto cultural no qual o instrumento será empregado. Esse processo tem como propósito identificar possíveis erros ocorridos nas etapas anteriores e obter sugestões para melhor adaptação de uma primeira versão do questionário (Q1) em português. Todos os membros do comitê tiveram acesso às versões produzidas em cada etapa (S1, R1 e R2), além do questionário original em inglês, para comparação. 
Foi solicitado aos especialistas que avaliassem, para cada item e para o questionário como um todo, a adequação dos seguintes quesitos: correspondência da S1 com a versão original, pertinência/importância, clareza, vocabulário, objetividade, aplicabilidade ao contexto brasileiro e sequência instrucional dos itens. Para a avaliação desses quesitos, adotou-se uma escala Likert de 1 a 4 ( 1 = adequado; 2 = adequado com poucas alterações; $3=$ adequado com muitas alterações e 4 = inadequado). Mediante análise da avaliação dos itens pelo comitê de especialistas, foi calculado, de forma adaptada, o índice de validade de conteúdo (IVC) [onde IVC = (número de respostas 1 e 2)/(número total de especialistas)], sendo considerado índice adequado o valor acima de $0,8^{35}$. Também foi solicitado aos especialistas que avaliassem a correspondência das retraduções (R1 e R2) de cada item em relação ao questionário original $(1=$ inalterado; $2=$ pouco alterado; $3=$ muito alterado e 4 = completamente alterado) ${ }^{35,36}$.

A quarta etapa (Etapa 4) consistiu na elaboração de uma versão síntese das retraduções (RS1) e na versão Q1. A versão síntese foi produzida a partir da comparação das duas retraduções avaliadas pelo comitê de especialistas, por um terceiro tradutor (R3), proficiente e fluente nos dois idiomas, com formação em medicina e amplo conhecimento na temática sobre experiências adversas na infância, além de atuante na área da saúde coletiva (MCV). A versão Q1 foi, então, produzida considerando o julgamento da adequação de cada item do questionário pelo comitê de especialistas, e suas propostas de melhor adequação em itens considerados inadequados, desde que fossem pertinentes ao contexto original do ACE-IQ pelos pesquisadores, de acordo com os documentos de instrução da $\mathrm{OMS}^{34}$.

A última etapa (Etapa 5) da equivalência semântica constituiu-se na realização de um pré-teste (Pré-teste 1) com a versão Q1 em uma amostra de voluntários estudantes e funcionários de um programa de pós-graduação, composta por nove mulheres e dois homens, com o intuito de avaliar a aceitabilidade e a compreensão dos itens e a reação emocional dos entrevistados aos temas abordados ${ }^{32}$. A idade dos participantes variou de 28 a 48 anos, com escolaridade do ensino médio ao doutorado. O questionário (Q1) foi aplicado de forma padronizada, através de entrevistas face a face conduzidas por um dos pesquisadores (FGP).

Uma escala verbal numérica adaptada ${ }^{25}$ foi utilizada pelos entrevistados para que avaliassem a facilidade de compreensão de cada item do questionário. A pergunta norteadora para todos os itens era "Você entendeu o que foi perguntado?", sendo três as respostas possíveis: 1 = não entendi nada; 2 = entendi, mas tenho dúvidas; 3 = entendi perfeitamente e não tenho dúvidas. Também foi solicitado aos entrevistados que explicassem o que entenderam sobre cada item do questionário, a fim de avaliar se cada questão reproduzia o sentido do item original. Ao final da aplicação do questionário, os participantes responderam às seguintes perguntas, ainda em entrevista face a face com a pesquisadora (FGP): a) todos os itens do instrumento apresentam opções de resposta satisfatórias?; b) os termos utilizados lhe são familiares?; c) você considera que algum termo ou trecho é ambíguo ou difícil de entender?; e d) sobre os itens que não foram compreendidos, ou de uma maneira geral, você gostaria de apresentar alguma sugestão para melhorar o questionário? As perguntas eram abertas e todas as respostas foram exploradas e anotadas.

A partir das considerações e dúvidas obtidas nessa etapa, uma segunda versão (Q2) foi produzida e apresentada a dez novos voluntários, sendo oito mulheres e dois homens. Esse grupo foi composto por estudantes e funcionários de um programa de pós-graduação em saúde coletiva com idade entre 19 e 42 anos, escolaridade variando do nível médio (técnico profissionalizante) até o doutorado. Foram realizadas entrevistas face a face, em que os participantes fizeram a leitura do questionário em voz alta explicando o que entenderam a respeito de cada item (Pré-teste 2). A versão Q2 foi, então, ajustada e produzida a versão final do ACE-IQ adaptado para uso no Brasil, denominado "Questionário Internacional de Experiências Adversas na Infância (EAI-QI)”, disponível no Quadro. Foram mantidas a numeração e a codificação de todos os itens conforme o instrumento original, para facilitar a comparação com outros estudos e a compilação de múltiplos bancos de dados (Quadro). 


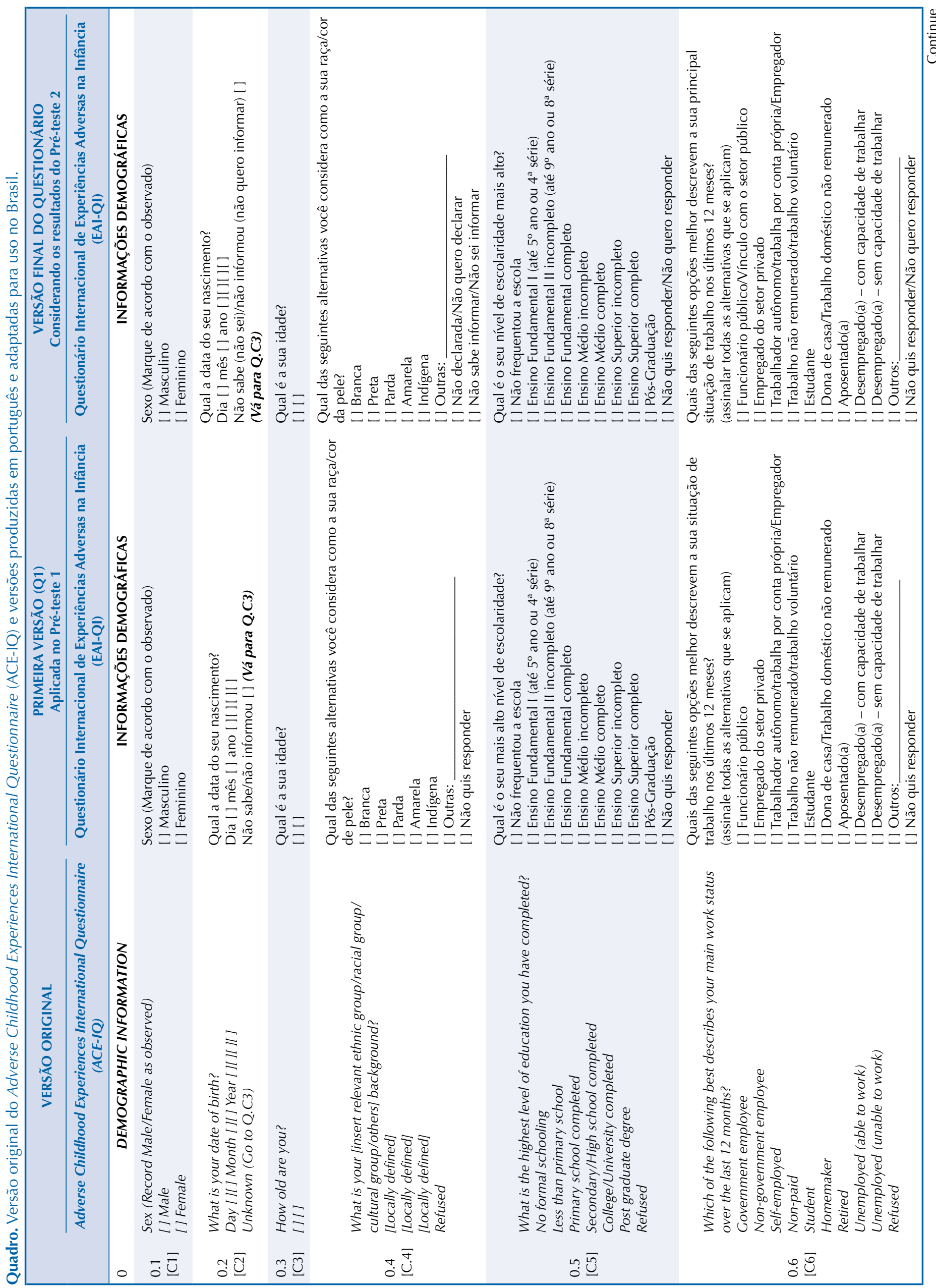




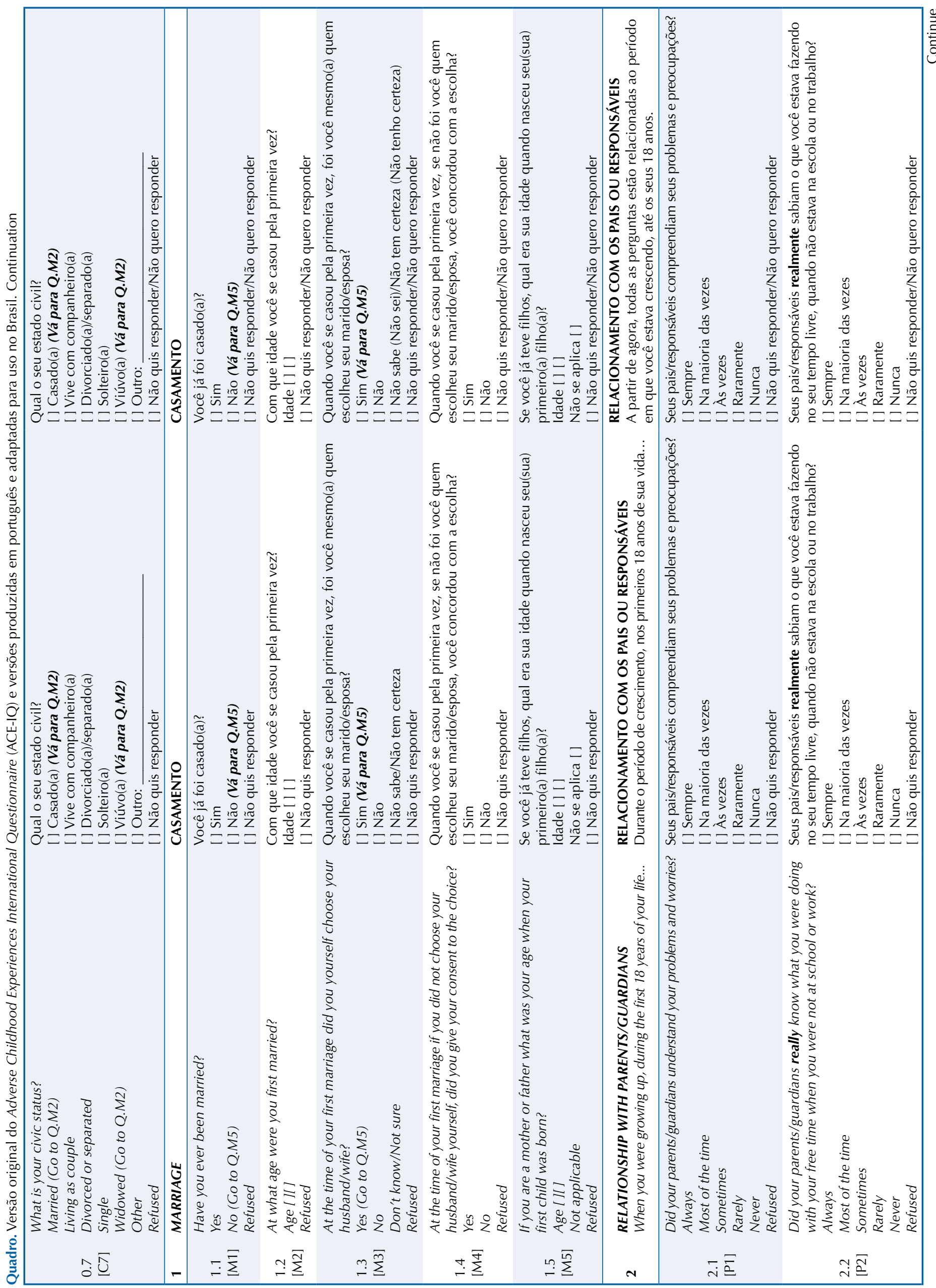




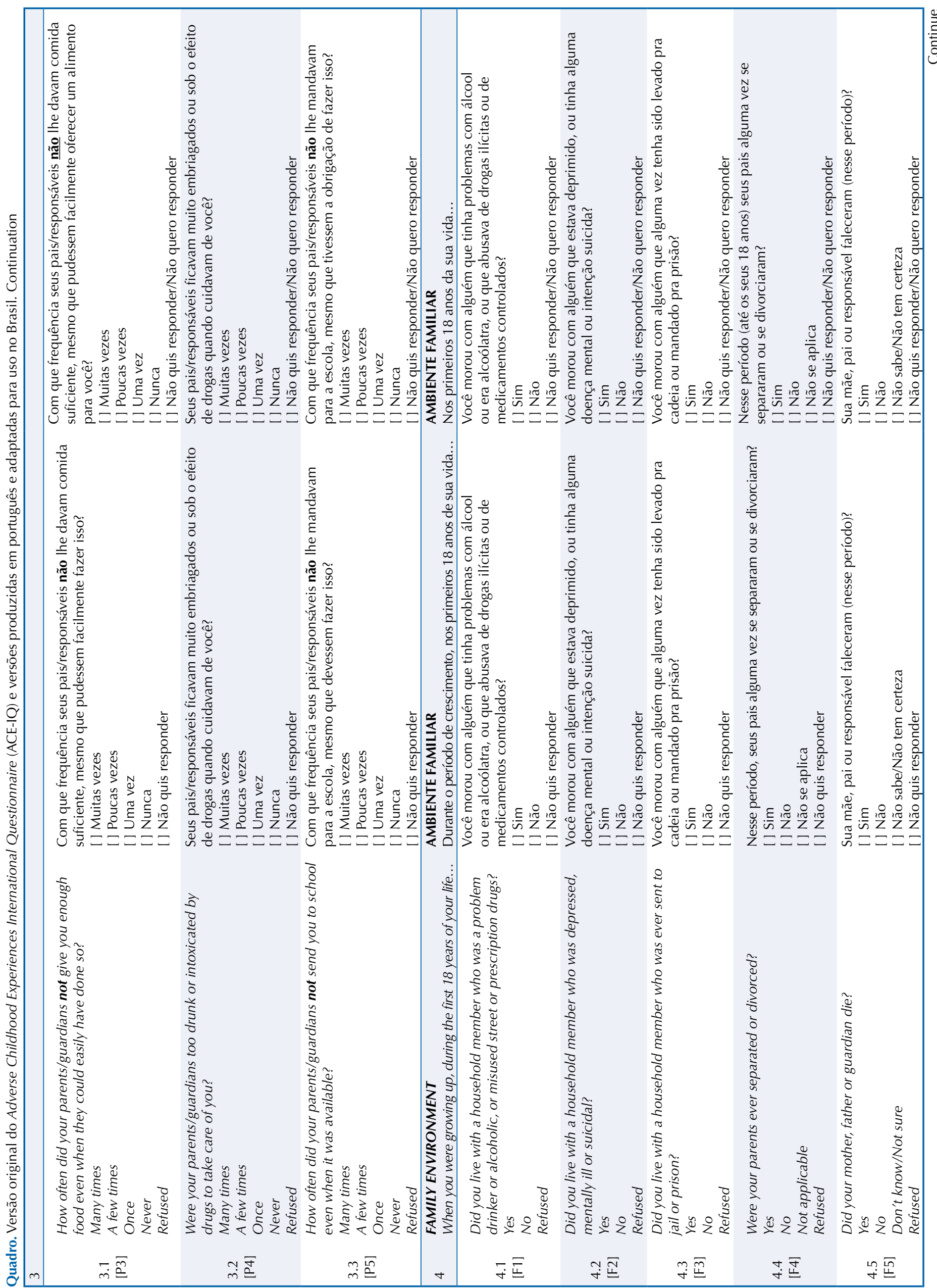




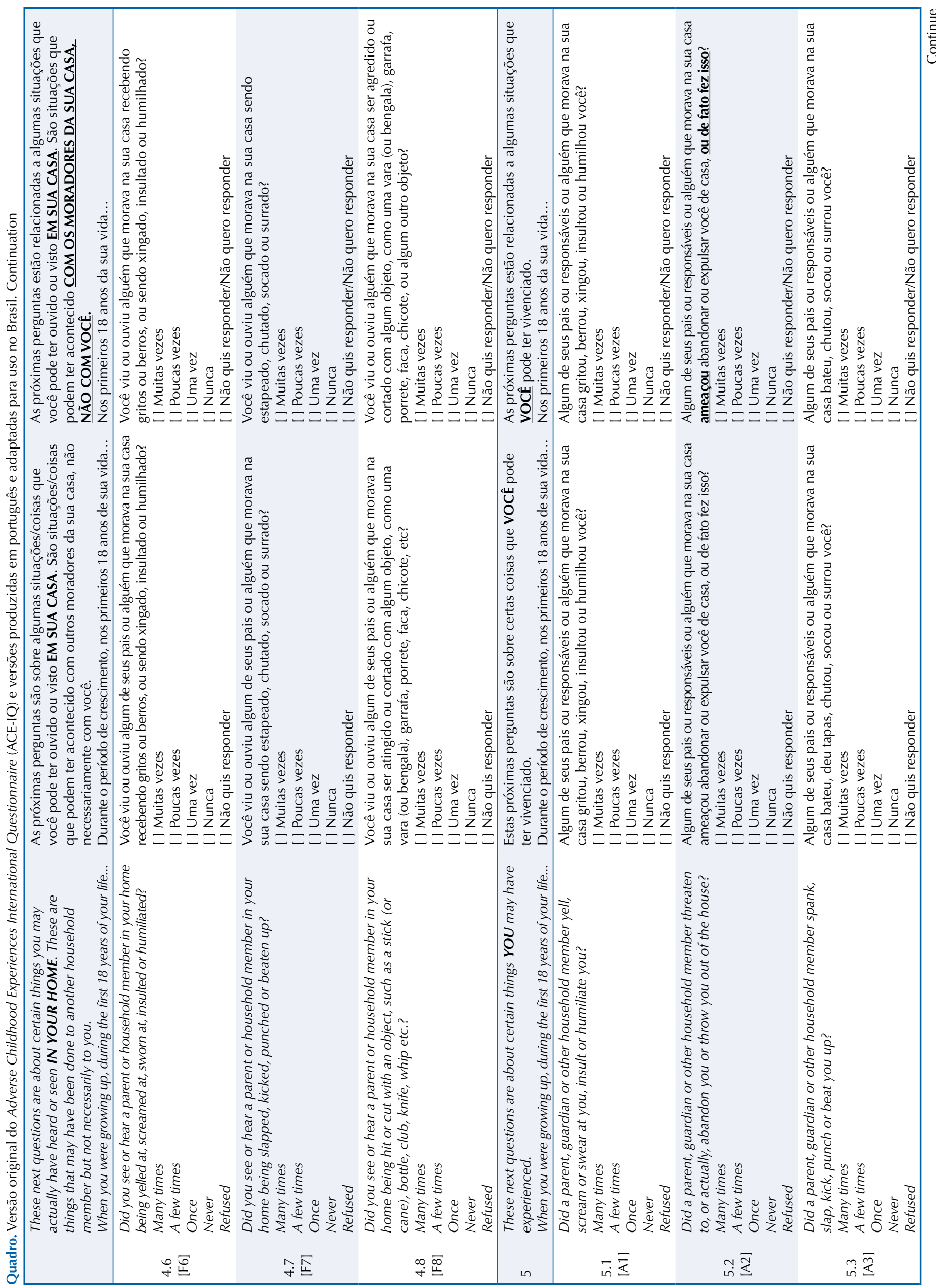




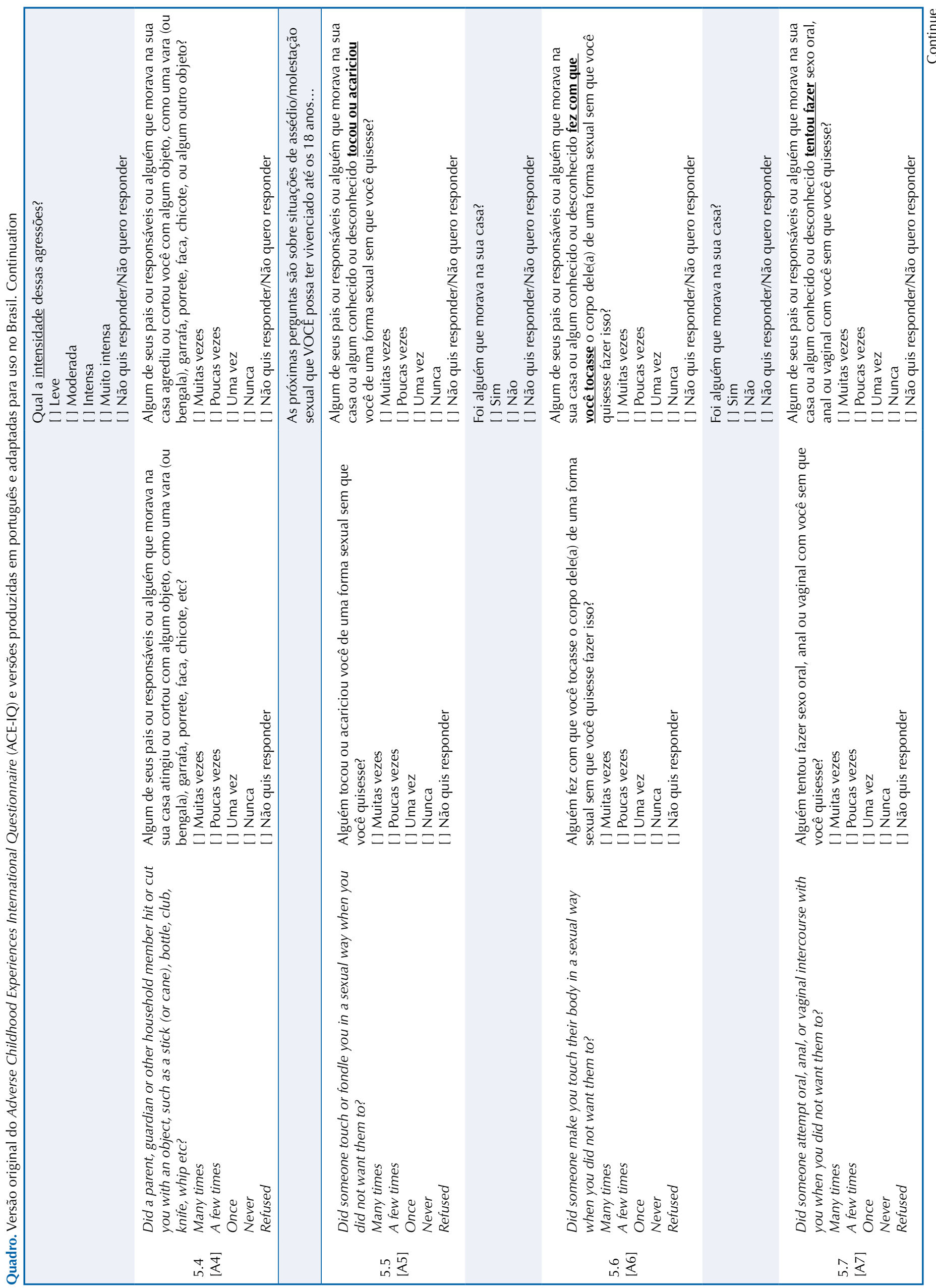




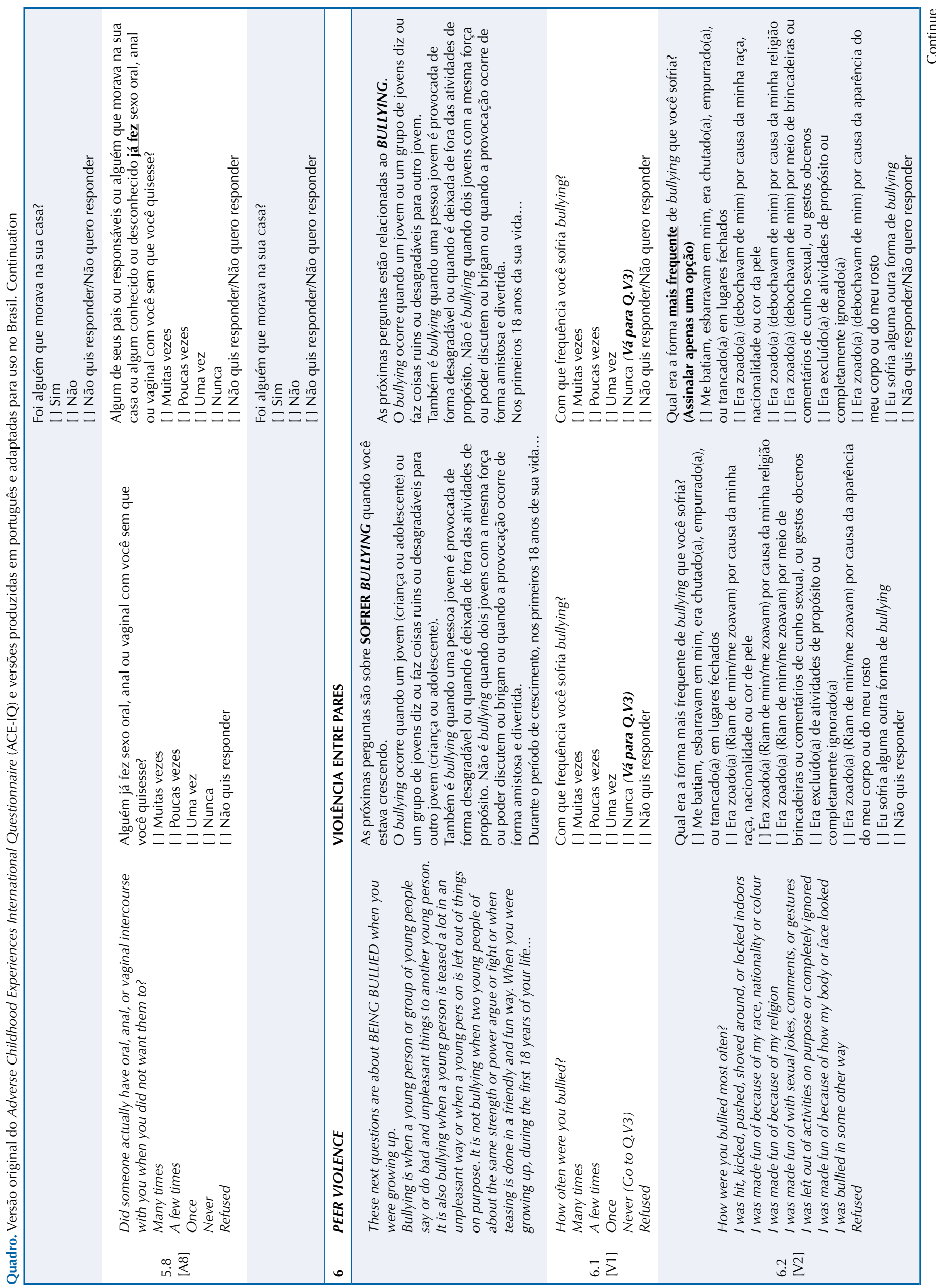




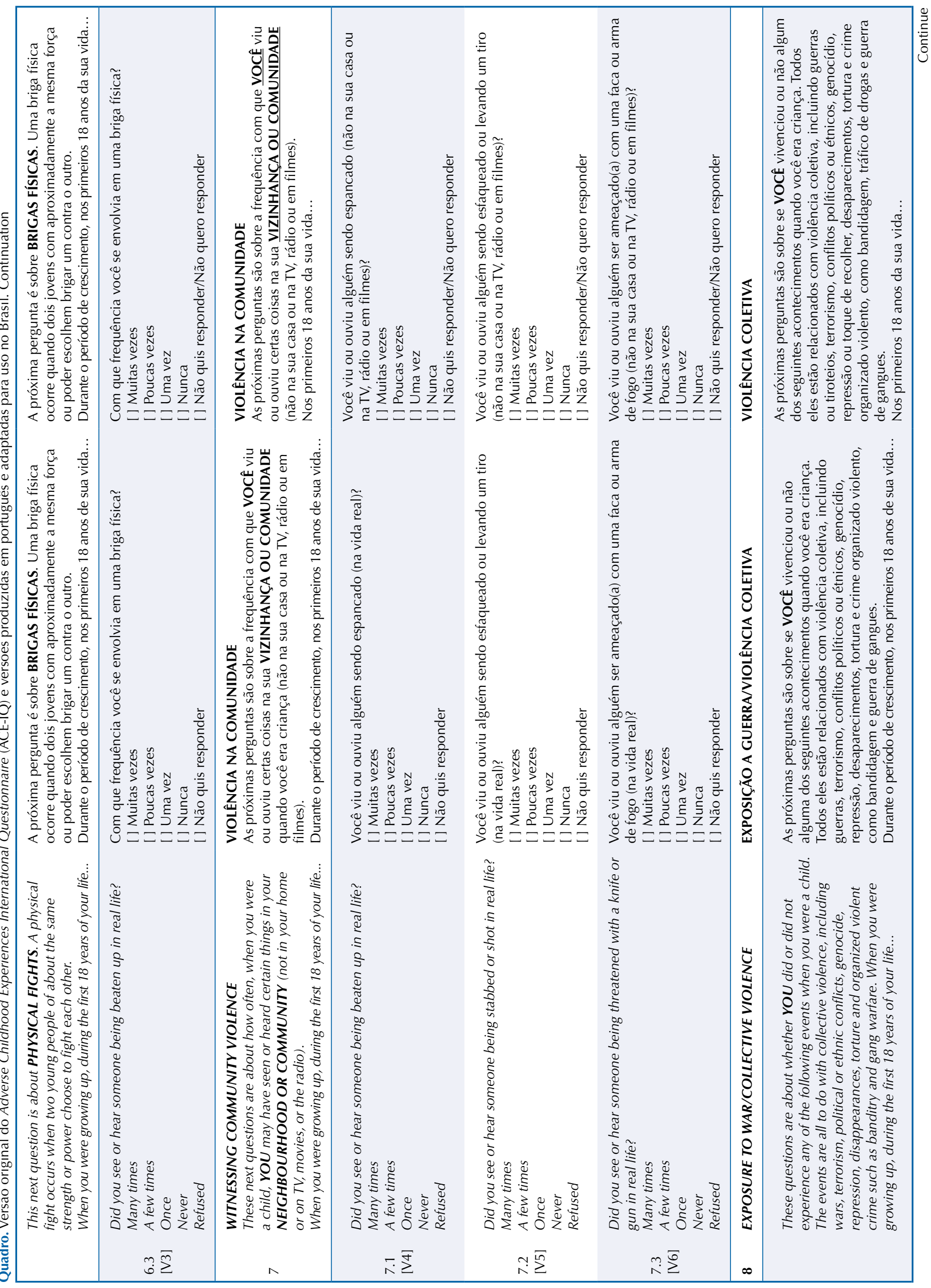




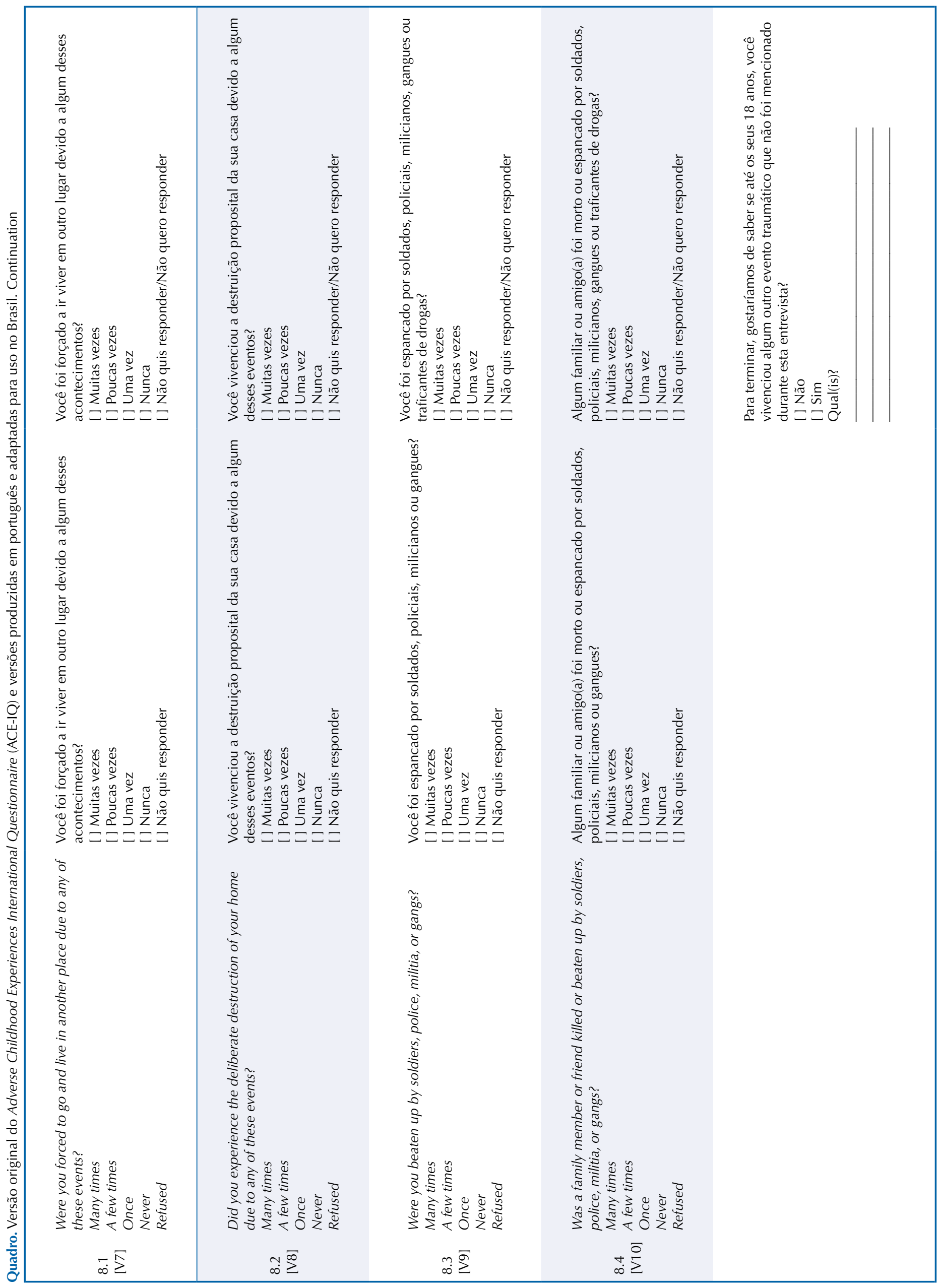




\section{Procedimentos Éticos}

A autorização para conduzir o processo de adaptação transcultural do ACE-IQ foi requerida ao coordenador de prevenção de violência da OMS, e concedida via correio eletrônico.

O projeto de adaptação transcultural do ACE-IQ foi aprovado pelo Comitê de Ética e Pesquisa do Centro de Ciências da Saúde da UFES (Cepe/Ufes 2.141.917). Todos os participantes assinaram o termo de consentimento livre e esclarecido.

\section{RESULTADOS}

A primeira e a última versão do questionário estão apresentadas no Quadro, juntamente com a versão original do instrumento, em inglês, disposta na primeira coluna. A versão final do EAI-QI está disponível no site da OMS: https://www.who.int/publications/m/item/ adverse-childhood-experiences-international-questionnaire-(ace-iq)

Apenas três dos 43 itens de ambas as retraduções, quando comparadas ao instrumento original pelo comitê de especialistas, foram consideradas "muito alteradas" ou "completamente alteradas". As discrepâncias encontradas ocorreram nas categorias de raça/cor autodeclarada (item C4), escolaridade (C5) e ocupação (C6), e foram resolvidas pelo R3, de acordo com os termos padronizados pelo Instituto Brasileiro de Geografia e Estatística (IBGE). Essas diferenças já haviam sido identificadas nas duas traduções iniciais. Ainda em relação às retraduções, os demais itens foram considerados pelos especialistas como "inalterados" ou "pouco alterados", tendo sido considerada mais adequada a R2 em relação à R1, quanto à correspondência à versão original. Todos os itens foram revistos e, quando necessário, ajustados pelo R3.

$\mathrm{Na}$ avaliação global do questionário, o IVC foi correspondente a 1,0 em quase todos os quesitos de julgamento pelo comitê de especialistas, considerando a correspondência da S1 com a versão original em relação a pertinência/importância, clareza, vocabulário, objetividade, aplicabilidade ao contexto brasileiro e sequência instrucional dos itens. Dos 43 itens, apenas dois (C4 e A6) apresentaram o IVC < 0,7 (Tabela), sendo ajustados pelo R3, tanto na RS1 quanto na Q1. No item C4, os especialistas indicaram a inclusão da opção de resposta "outras", considerando que algumas pessoas podem não se identificar com as alternativas apresentadas. No item A6, referente ao abuso sexual, foram apresentados pelos especialistas diversos formatos de reescrita do item, para frisar a ideia de que o respondente foi "forçado" a algo que não quisesse; no entanto, quando a questão original foi colocada em pré-teste, não foram observadas dificuldades de interpretação e, portanto, as sugestões de modificação feitas pelo comitê de especialistas não foram acolhidas. No geral, $73 \%$ dos quesitos avaliados receberam a pontuação máxima no IVC (1,0); em $21 \%$ o IVC foi 0,87; e em $4 \%, 0,75$, sendo considerado adequado um valor de IVC $>0,8^{33}$. Apesar dessa pontuação satisfatória, todas as sugestões recomendadas pelos especialistas foram consideradas e, quando possíveis e pertinentes, incorporadas ao Q1.

\section{Pré-teste 1}

No primeiro pré-teste, conduzido com 11 participantes, os itens P3 e V2 apresentaram as menores médias de compreensão $(2,72)$, avaliadas pela escala verbal de três pontos.

O item P3, que avalia a não provisão de alimentação adequada, foi interpretado erroneamente por alguns entrevistados como sendo devido à falta de condições financeiras dos pais ou responsáveis, porém a negligência física envolve o não provimento de condições básicas ao desenvolvimento infantil (alimentação, vestuário, assistência médica) na ausência de adversidade econômica ${ }^{37}$. Interpretação semelhante ocorreu no item P5 (média 2,82), no qual além da dificuldade financeira, foi aventada a impossibilidade de acesso e/ou a indisponibilidade local de escolas. 
Tabela. Itens do questionário que apresentaram quesitos com IVC inferior a 0,7 na avaliação do comitê de especialistas.

\begin{tabular}{|c|c|c|c|}
\hline \multirow{2}{*}{ Quesitos avaliados } & Item C4 & Item A6 & \multirow{2}{*}{$\%$ IVC $>0,8^{a}$} \\
\hline & IVC & IVC & \\
\hline Correspondência a versão original & 0,62 & 0,62 & 95 \\
\hline Pertinência/importância & 0,75 & 0,87 & 93 \\
\hline Clareza & 0,37 & 0,62 & 93 \\
\hline Vocabulário & 0,50 & 0,87 & 93 \\
\hline Objetividade & 0,62 & 0,87 & 93 \\
\hline Aplicável ao modelo brasileiro & 0,50 & 1 & 95 \\
\hline Sequência instrucional & 0,75 & 1 & 98 \\
\hline
\end{tabular}

IVC: índice de validade de conteúdo.

a Percentual de todos os cálculos de IVC nos 43 itens do questionário separado por quesito avaliado pelo comitê de especialista.

O item V2 foi resolvido com a inserção da instrução para que fosse escolhida apenas uma alternativa, referente à forma mais frequente de bullying, pois os participantes tendiam a marcar mais de uma resposta.

O item A3 foi discutido entre os pesquisadores após indicação dos participantes, no Pré-teste 1, de que a expressão "deu tapas"(dentre todas as outras formas de agressão) poderia não representar agressão física grave ou, ainda, que tais situações descritas no item pudessem ser entendidas como uma forma de correção disciplinar, e não como abuso físico. Esse resultado levou a ponderações e recomendações sugeridas pelos pesquisadores (ver "Limitações do instrumento e recomendações").

Nos itens de A5 a A8, todos os entrevistados que sofreram abuso sexual manifestaram dúvidas em relação ao que estava sendo avaliado, isto é, se o abuso se restringia ao ambiente domiciliar e, consequentemente, foi cometido por membro(s) da família, ou se incluía qualquer abuso sexual sofrido. Isso se deu porque, nessa seção, há uma mudança abrupta e sem explicação prévia no modo de formulação das perguntas, em relação às seções anteriores. Estas eram precedidas da frase "Algum de seus pais ou responsáveis ou alguém que morava na sua casa...?”, e, na seção relativa a abuso sexual, a frase introdutória passou a ser "Alguém...", sem que houvesse nenhuma especificação do agressor. Segundo as orientações para a utilização de ACE-IQ ${ }^{34}$, esses itens avaliam o abuso sexual infantil cometido por qualquer pessoa - familiares, conhecidos ou desconhecidos da criança. Para resolver essa dificuldade e esclarecer as possíveis dúvidas, optou-se por modificar a pergunta introdutória, de forma que as quatro questões dessa seção passaram a ser precedidas pela frase "Algum de seus pais ou responsáveis ou alguém que morava na sua casa ou algum conhecido ou desconhecido...”, sendo, ainda, incluído um subitem em cada questão, para distinguir se os abusadores eram ou não moradores da casa (ver "Limitações do instrumento e recomendações").

Os participantes do Pré-teste 1 fizeram algumas sugestões: 1) trocar a ordem do item C5 de "Qual é o seu mais alto nível de escolaridade?" para "Qual o seu nível de escolaridade mais alto?”; 2) deixar apenas uma opção de escolha para a situação de trabalho nos últimos 12 meses (C6), apesar de terem demonstrado dificuldade em escolher apenas uma alternativa de resposta; 3) ajustar a instrução, antecedendo a seção de violência doméstica (F6-8), retirando a palavra "coisas" e a expressão "não necessariamente com você"; 4) trocar a palavra "atingido" por "agredido" em F8; e 5) retirar a expressão "exposição a guerra” e incluir os termos "tiroteios e tráfico de drogas" nas instruções que antecedem as questões sobre violência coletiva (V7-10).

Foi incluído, ainda, um último item no questionário - "Durante o período de crescimento, nos primeiros 18 anos de sua vida, você vivenciou algum outro evento traumático que não foi mencionado durante a entrevista?" - e, em caso afirmativo, um espaço aberto para resposta (ver "Limitações do instrumento e recomendações"). 


\section{Pré-teste 2}

Todos os itens adaptados e as modificações sugeridas a partir dos resultados do Pré-teste 1 objetivaram empregar termos coloquiais utilizados no contexto brasileiro, de mais fácil compreensão pela população geral, dando origem a uma versão modificada do questionário (Q2), que foi avaliada no Pré-teste 2. A partir da leitura de cada item pelos participantes e do relato de sua compreensão, sugestões de modificações do texto foram solicitadas quando o conteúdo era diferente do original ou ofertadas por elas, quando julgavam que a questão poderia ser melhor formulada.

Após o Pré-teste 2, decidiu-se modificar parte dos itens P3 (“...mesmo que pudessem facilmente oferecer um alimento para você?”) e P5 (“....mesmo que tivessem a obrigação de fazer isso?”) para melhor compreensão da questão (Quadro).

O item C6 foi testado de duas formas: 1) permitindo a escolha de todas as opções que correspondessem à situação de trabalho dos entrevistados nos últimos 12 meses; e 2) de apenas uma resposta, que representasse a principal atividade profissional/ocupacional. Embora a instrução do questionário original solicite apenas uma resposta, optou-se pelo uso de múltiplas alternativas considerando a dificuldade para escolher apenas uma resposta no Pré-teste 1, talvez refletindo a frequente multiplicidade de empregos no Brasil. Outras pequenas mudanças foram realizadas após o Pré-teste 2 e incorporadas à versão final do instrumento, apresentada no Quadro.

\section{DISCUSSÃO}

A utilização de instrumentos padronizados de avaliação tornou-se uma prática necessária nas ciências da saúde, visando o aprimoramento do conhecimento científico. A sistematização da coleta de informações promove a redução de divergências, aumentando a qualidade da informação e, consequentemente, possibilitando a comparabilidade de resultados. Além disso, produz melhor embasamento para planejar políticas públicas e condutas clínicas ${ }^{31}$.

Os questionários estruturados são instrumentos amplamente utilizados em pesquisas epidemiológicas, em diversas áreas de interesse. Antes de se considerar o desenvolvimento de algum novo método de avaliação, faz-se necessária uma rigorosa revisão bibliográfica para a identificação dos instrumentos já existentes que permitam a avaliação desejada do objeto de estudo ${ }^{33}$. Em relação aos eventos traumáticos vivenciados na infância, é possível encontrar uma variedade de instrumentos disponívei ${ }^{24,36}$. Ao identificar algum instrumento adequado aos objetivos do estudo que não esteja disponível no idioma da população a ser estudada, a melhor alternativa seria dar início à adaptação transcultural ${ }^{38}$.

A disponibilização do ACE-IQ para uso no Brasil, através da adaptação transcultural aqui descrita, possibilitará a utilização de um instrumento proposto pela OMS que permite a investigação de um número maior de EAI do que outros instrumentos em português, com o intuito de estabelecer avaliações estruturadas e produzir medidas comparáveis entre diversos países, com vistas à construção de perfis epidemiológicos da exposição a adversidades e eventos traumáticos na infância.

Neste artigo, apresenta-se a equivalência semântica do ACE-IQ da versão produzida em português vigente no Brasil. A adaptação transcultural é um processo minucioso e a equivalência semântica é considerada apenas uma de suas etapas ${ }^{32}$, embora não haja consenso sobre a forma mais adequada para a execução da adaptação transcultural e diversas abordagens metodológicas tenham sido propostas ${ }^{30,31,32,39,40}$.

A validade de conteúdo foi apresentada como parte da equivalência semântica, consistindo no julgamento sobre a representatividade e clareza de cada item do instrumento, segundo critérios pré-estabelecidos, avaliando-se, assim, a concordância entre os juízes sobre a adequação do conteúdo ao que o instrumento se propõe a medir ${ }^{35,41}$. 
Apesar de ser uma avaliação apontada como subjetiva por alguns autores ${ }^{35,36}$ é um processo frequentemente realizado nas ciências da saúde ${ }^{42,43,44}$, não dispensando, no entanto, a avaliação de outras medidas psicométricas ${ }^{45}$. Constatou-se boa equivalência semântica entre a versão em português e a original, através da validade de conteúdo, considerando-se a avaliação do comitê de especialistas e o cálculo do IVC e das médias de compreensibilidade durante os pré-testes.

Este estudo deve ser considerado à luz de algumas limitações. Os pré-testes foram realizados em amostras de voluntários não representativas da população geral adulta brasileira e, portanto, poderá haver variabilidade na compreensão dos itens ou expressões em amostras com distinta distribuição de idade, escolaridade ou classe socioeconômica, que poderá ser apreciada em estudos posteriores, quando o questionário produzido for aplicado em outras amostras. $\mathrm{O}$ instrumento original apresenta algumas expressões idiomáticas que não têm equivalência direta na língua portuguesa vigente no Brasil, tendo suscitado a exploração extensiva de alternativas aproximadas entre os respondentes e o comitê de especialistas. A avaliação da violência comunitária e coletiva envolve múltiplos aspectos, geralmente dependentes do contexto sociocultural da população investigada e socioeconômico/político da região/país, havendo itens que não são relevantes para o contexto da população brasileira, como a exposição a situações de guerra, terrorismo, genocídio, conflitos políticos e étnicos, entre outras. Por outro lado, a investigação de violência comunitária, extremamente relevante em estudos brasileiros, associada à presença de tráfico de drogas e de ações milicianas e/ ou policiais, especialmente em regiões socialmente mais vulneráveis, com a exposição direta a brigas de gangues e balas perdidas, foi incluída no EAI-QI como violência coletiva, havendo, portanto, uma convergência desses contextos na avaliação de alguns estratos da população brasileira.

\section{Limitações do Instrumento e Recomendações}

O instrumento adaptado neste estudo, assim como a maior parte dos instrumentos que avaliam EAI, foi projetado para a investigação da exposição a EAI em adultos (idade $\geq 18$ anos), podendo ocorrer vieses de memória na coleta de informação. Além disso, indivíduos expostos a violências de maior gravidade têm risco aumentado de óbito e, portanto, o espectro mais grave da exposição não poderá ser capturado por essa forma de avaliação.

O ACE-IQ incorporou, junto à avaliação de EAI já estudada, a investigação de outras exposições, como bullying e violência coletiva ou na comunidade. Apesar dessa maior abrangência na identificação de EAI, de grande utilidade em pesquisas epidemiológicas, o instrumento apresenta limitações em sua forma de avaliar algumas das EAI. Assim, é pertinente apresentar algumas considerações e recomendações julgadas relevantes, tanto para o aprimoramento do instrumento, como para guiar a sua utilização, análise e interpretação de resultados em estudos que utilizam o EAI-QI. São elas:

1. Idade: todas as questões são precedidas por uma frase introdutória determinando que sejam consideradas apenas as experiências que tenham ocorrido "durante o período de crescimento, até os 18 anos de idade”. A exposição a EAI pode ter impacto deletério diferencial dependendo da idade de ocorrência. As crianças pequenas têm maior fragilidade física, são mais impotentes diante da violência, são mais vulneráveis ante a negligência e têm menor compreensão do que se passa à sua volta. Por outro lado, os adolescentes tendem a sofrer maus-tratos com maior intensidade e gravidade do que as crianças menores, mas, também, podem ser capazes de apresentar algum grau de enfrentamento e/ou de esquiva. Assim, sugere-se que a investigação da ocorrência de EAI seja relativa a, pelo menos, dois períodos distintos, infância (até os 10 anos) e adolescência (dos 11 aos 18 anos). Além disso, a duração da exposição a EAI também tem implicação direta nas consequências negativas, devendo ser incluída no questionário.

2. Gravidade do abuso físico: na questão A3, estão juntas expressões que envolvem variadas intensidades de agressão física (desde "deu tapas" a "chutou” e "socou, surrou”), 
gerando dúvidas na resposta, já que algumas formas de agressão física leve podem ser culturalmente justificadas como métodos disciplinares. Uma tentativa de resolver essa dificuldade foi retirar a expressão "deu tapas". O abuso físico de uma criança é definido como "o uso intencional da força física que resulta, ou tem uma alta probabilidade de resultar, em danos à saúde, à sobrevivência, ao desenvolvimento ou à dignidade da criança”,36. Assim, sugere-se acrescentar subitens para classificar a intensidade das agressões (leve, moderada, intensa ou muito intensa) e produzir estimativas mais robustas acerca do abuso físico infantil.

3. Perpetração de abuso sexual: nos itens A5-A8, há uma mudança abrupta no formato das questões que investigam a ocorrência de abuso sexual, uma vez que todos os itens anteriores eram estritamente relativos ao ambiente familiar. Sugere-se a inserção de uma frase introdutória para esse módulo, esclarecendo que o objetivo desse módulo é investigar o abuso sexual ocorrido antes dos 18 anos e perpetrado por qualquer pessoa, conhecido ou não da vítima. Sugere-se, ainda, que seja acrescentado um subitem a todas as questões, identificando se o agressor é ou não morador da casa, já que essa informação tem relevância na compreensão do impacto dos diversos tipos de abuso sexual perpetrados contra crianças e adolescentes. Usualmente, o abuso sexual que ocorre dentro do ambiente doméstico tem caráter repetitivo sem que a criança tenha, inicialmente, consciência e discernimento acerca do abuso. Assim, o perpetrador, que deveria cuidar e proteger, tende a se beneficiar da relação de confiança e poder, aproveitando-se da vulnerabilidade, imaturidade e insegurança, para impor $\grave{a}$ criança ou ao adolescente, sob ameaças e/ou força física, a agressão sexual e o silêncio ${ }^{47}$. Fora do ambiente doméstico, o abuso sexual tende a ocorrer de forma eventual, e a vítima é refém do agressor somente durante a agressão per se. De qualquer modo, o abuso sexual é um fenômeno traumático com graves consequências e a identificação dos agressores pode ser fundamental para a implementação de estratégias preventivas, além de ter relevância clínica no manejo terapêutico das vítimas de abuso sexual.

4. Bullying: somente a forma mais frequente de bullying é investigada, desconsiderando a multiplicidade e a gravidade das agressões. Além disso, não é investigada a possibilidade de que a vítima seja também agressora, tendo em vista que crianças e adolescentes vítimas de EAI podem se tornar agressores, perpetuando um ciclo de abusos e naturalizando a violência na resolução de problemas. Assim, sugere-se que múltiplas alternativas de resposta sejam permitidas e que seja incluída a investigação de perpetração de bullying.

5. Outros tipos de EAI: a compreensão acerca das EAI modificou-se ao logo da história e, com isso, novas categorias foram definidas e exploradas na construção de novos questionários. Apesar do ACE-IQ apresentar maior variedade de EAI do que os instrumentos anteriores, algumas adversidades descritas em outros questionários não foram incluídas, como, por exemplo, a exposição a adversidades econômicas e a ocorrência de doenças físicas e/ou acidentes graves. Sugere-se, assim, que seja incluído um item final para identificar a ocorrência de outros eventos traumáticos não avaliados.

\section{CONCLUSÃO}

O instrumento adaptado neste estudo apresentou boa equivalência semântica, tornando-se uma ferramenta disponível para a pesquisa epidemiológica no Brasil, permitindo a comparabilidade entre estudos nacionais e internacionais. Além disso, pode contribuir para o conhecimento científico acerca do impacto deletério das EAI na vida adulta da população brasileira, com grande relevância para o campo da saúde coletiva. A investigação sistemática da EAI tem, também, importância clínica, ao prover informações do contexto histórico traumático do paciente, possibilitando uma avaliação mais abrangente, permitindo diagnósticos mais precisos e tratamentos mais adequados e reduzindo, assim, custos do sistema de saúde, perda de produtividade e sofrimento e incapacidade pessoal. 
Por fim, pode prover informações relevantes para fundamentar o planejamento e a formulação de políticas públicas de prevenção e intervenção, visando minimizar a exposição a experiências adversas e traumáticas na infância e adolescência.

\section{REFERÊNCIAS}

1. Martins CBG, Mello-Jorge MHP. Maus-tratos infantis: um resgate da história e das políticas de proteção. Acta Paul Enferm. 2010;23(3):423-8. https://doi.org/10.1590/S0103-21002010000300018

2. Oliveira RV, Pais LG. A origem dos maus-tratos: revisão sobre a evolução histórica das percepções de criança e maus-tratos. Psychol Community Health. 2014;3(1):36-49. https://doi.org/10.5964/pch.v3i1.63

3. Felitti VJ, Anda RF, Nordenberg D, Williamson DF, Spitz AM, Edwards V, et al. Relationship of abuse and household dysfunction to many of the leading causes of death in adults: the Adverse Childhood Experiences (ACE) Study. Am J Prev Med. 1998;14(4):245-58. https://doi.org/10.1016/s0749-3797(98)00017-8

4. Felitti VJ, Anda R. The relationship of adverse childhood experiences to adult medical disease, psychiatric disorders and sexual behavior: implications for healthcare. In: Lanius RA, Vermetten E, Pain C, editors. The impact of early trauma on health and disease: the hidden epidemic. Cambridge (UK): Cambridge University Press; 2010. p. 77-87.

5. Almuneef M, Qayad M, Aleissa M, Albuhairan F. Adverse childhood experiences, chronic diseases, and risky health behaviors in Saudi Arabian adults: a pilot study. Child Abuse Negl. 2014;38(11):1787-93. https://doi.org/10.1016/j.chiabu.2014.06.003

6. Pinto VCP, Alves JFC, Maia AC. Adversidade na infância prediz sintomas depressivos e tentativas de suicídio em mulheres adultas portuguesas. Estud Psicol (Campinas). 201532(4):617-25. https://doi.org/10.1590/0103-166X2015000400005

7. Musa S, Peek-Asa C, Jovanovic N, Selimovic E. Association of adverse childhood experiences and health risk behaviors among young adults visiting a regional primary healthcare center, Federation of Bosnia and Herzegovina. PloS One. 2018;13(3):e0194439. https://doi.org/10.1371/journal.pone.0194439

8. Clemmons JC, DiLillo D, Martinez IG, DeGue S, Jeffcott M. Co-ocurring forms of child maltreatment and adjustment reported by Latina college students. Child Abuse Negl. 2003;27(7):751-67. https://doi.org/10.1016/s0145-2134(03)00112-1

9. Kessler RC, McLaughlin KA, Green JG, Gruber MJ, Sampson NA, Zaslaysky AM, et al. Childhood adversities and adult psychopathology in the WHO World Mental Health Surveys. Br J Psychiatry. 2010;197(5):378-85. https://doi.org/10.1192/bjp.bp.110.080499

10. Scott KM, Smith DR, Ellis PM. Prospectively ascertained child maltreatment and its association with DSM-IV mental disorders in young adults. Arch Gen Psychiatry. 2010;67(7):712-9. https://doi.org/10.1001/archgenpsychiatry.2010.71

11. Huh HJ, Kim KH, Lee HK, Chae JH. The relationship between childhood trauma and the severity of adulthood depression and anxiety symptoms in a clinical sample: the mediating role of cognitive emotion regulation strategies. J Affect Disord. 2017;213:44-50. https://doi.org/10.1016/j.jad.2017.02.009

12. Heim C, Wagner D, Maloney E, Papanicolau DA, Solomon L, Jones JF, et al. Early adverse experience and risk for chronic fatigue syndrome: results from a population -based study. Arch Gen Psychiatry. 2006;63(11):1258-66. https://doi.org/10.1001/archpsyc.63.11.1258

13. Viana MC, Lim CCW, Pereira FG, Aguilar-Gaxiola S, Alonso J, Bruffaerts R, et al. Previous mental disorders and subsequent onset of chronic back or neck pain: findings from 19 countries. J Pain. 2018;9(1):99-110. https://doi.org/10.1016/j.jpain.2017.08.011

14. Dube SR, Williamson DF, Thompson T, Felitti VJ, Anda RF. Assessing the realiability of retrospective reports of adverse childhood experiences among adult $\mathrm{HMO}$ members attending a primary care clinic. Child Abuse Negl. 2004;28(7):729-37. https://doi.org/10.1016/j.chiabu.2003.08.009

15. Hillis SD, Anda RF, Felitti VJ, Marchbanks PA. Adverse childhood experiences and sexual risk behaviors in woman: a retrospective cohort study. Fam Plann Perspect. 2001;33(5):206-11. https://doi.org/10.2307/2673783 
16. Faria APA, Lima CAB, Molina MC, Pereira FG, Coutinho ESF, Viana MC. Exposição a adversidades na infância e tabagismo. Rev Bras Pesq Saude. 2018;20(3):110-22. https://doi.org/10.21722/rbps.v20i3.24509

17. El Mhamdi S, Lemieu A, Ben Salah A, Bouanene I, Ben Salem K, al'Absi M. Exposure to community and collective violence during childhood and tobacco use patterns among young adults in Tunisia. Health Soc Care Community. 2018;26(6):935-45. https://doi.org/10.1111/hsc.12623

18. Brown DW, Anda RF, Tiemeier H, Felitti VJ, Edwards VJ, Croft JB, et al. Adverse childhood experiences and the risk of premature mortality. Am J Prev Med. 2009;37(5):389-96. https://doi.org/10.1016/j.amepre.2009.06.021

19. Bellis MA, Hughes K, Leckenby N, Hardcastle KA, Perkins C, Lowey H. Measuring mortality and the burden of adult disease associated with adverse childhood experiences in England: a national survey. J Public Health (Oxf). 2015;37(3):445-54. https://doi.org/10.1093/pubmed/fdu065

20. Metzler M, Merrick MT, Klevens J, Ports KA, Ford DC. Adverse childhood experiences and life opportunities: shifting the narrative. Child Youth Serv Rev. 2017;72:141-9. https://doi.org/10.1016/j.childyouth.2016.10.021

21. Schwanck RH, Silva MRS. Processos que sustentam o enfrentamento da experiência de abuso sexual na infância: um estudo de caso. Cienc Cuid Saude. 2006;5(3):380-8. https://doi.org/10.4025/cienccuidsaude.v5i3.5038

22. Bernstein D, Fink L. Childhood Trauma Questionnaire: a retrospective self-report. San Antonio, TX: The Psicological Corporation, 1998.

23. Martinez Montecinos RE, Cevallos Añasco R. Relación de las experiencias sexuales infantojuveniles com la confianza diádica y el temor a la intimidad, en estudiantes universitarios. Ter Psicol. 2008;26(2):229-39.

24. Roy CA, Perry JC. Instruments for the assessment of childhood trauma in adults. J Nerv Ment Dis. 2004;192(5):343-51. https://doi.org/10.1097/01.nmd.0000126701.23121.fa

25. Grassi-Oliveira R, Stein LM, Pezzi JC. Tradução e validação de conteúdo da versão em português do Childhood Trauma Questionnaire. Rev Saude Publica. 2006;40(2):249-55. https://doi.org/10.1590/S0034-89102006000200010

26. Pereira FG, Viana MC. Instrumentos mais utilizados na avaliação da exposição a experiências adversas na infância: uma revisão da literatura. Saude Debate. 2021;45(129):501-13.

27. World Health Organization. Addressing adverse childhood experiences to improve public health: expert consultation; 4-5 May 2009. Meeting Report. Geneva (CH): WHO; 2009 [citado 15 ago 2018]. Disponível em: https://www.who.int/violence_injury_prevention/violence/ activities/adverse_childhood_experiences/global_research_network/en

28. World Health Organization. Adverse Childhood Experiences International Questionnaire: piloty study review and finalization meeting, 4-5 May 2011, WHO Headquarters, Geneva. Meeting Report. Geneva (CH): WHO; 2011 [citado 15 ago 2018]. Disponível em: https://www.who.int/ violence_injury_prevention/violence/activities/adverse_childhood_experiences/global_research_ network_may_2011.pdf

29. Moraes CL, Hasselmann MH, Reichenheim ME. Adaptação transcultural para o português do instrumento "Revised Conflict Tactics Scales (CTS2)" utilizado para identificar violência entre casais. Cad Saude Publica. 2002;18(1):163-76. https://doi.org/10.1590/S0102-311X2002000100017

30. Guillemin F, Bombardier C, Beaton D. Cross-cultural adaptation of health-related quality of measures: literature review and proposed guidelines. J Clin Epidemiol. 1993;46(12):1417-32. https://doi.org/10.1016/0895-4356(93)90142-n

31. Beaton DE, Bombardier C, Guillemin F, Ferraz MB. Guidelines for the process of cross-cultural adaptation of self-reported measures. Spine. 2000;25(24):3186-91. https://doi.org/10.1097/00007632-200012150-00014

32. Reichenheim ME, Moraes CL. Operacionalização de adaptação transcultural de instrumentos de aferição usados em epidemiologia. Rev Saude Publica. 2007;41(4):665-73. https://doi.org/10.1590/S0034-89102006005000035

33. Kazi AM, Khalid W. Questionnaire designing and validation. J Pak Med Assoc. 2012;62(5):514-6.

34. World Health Organization. Adverse Childhood Experiences International Questionnaire (ACE-IQ). Geneva (CH): WHO; 2020 [citado 19 jul 2020]. Disponível em: https://www.who.int/ publications/m/item/adverse-childhood-experiences-international-questionnaire-(ace-iq) 
35. Rubio DM, Berg-Weger M, Tebb SS, Lee ES, Rauch S. Objectifying content validity: conducting a content validity study in social work research. Soc Work Res. 2003;27(2):94-104. https://doi.org/10.1093/swr/27.2.94

36. Alexandre NMC, Coluci MZO. Validade de conteúdo nos processos de construção e adaptação de instrumentos de medida. Cienc Saude Coletiva. 2011;16(7):3061-8. https://doi.org/10.1590/S1413-81232011000800006

37. Vilagut G, Saunders K, Alonso J. World mental health survey methods for studying mental-physical comorbidity. In: Von Korff MR, Scott KM, Gureje O, eds. Global Perspectives on Mental-Physical Comorbidity in the WHO World Mental Health Surveys. New York: Cambridge University Press, 2009. p. 29-50.

38. Harkness JA, Schoua-Glusberg A. Questionnaires in translation.In: Harkness J, editor. Cross cultural survey equivalence. Mannheim (DE): Zentrum für Umfragen, Methoden und Analysen -ZUMA; 1998 [citado 15 ago 2018]. (ZUMA-Nachrichten Spezial; $n^{\circ}$ 3). p. 87-126. Disponível em https://www.ssoar.info/ssoar/handle/document/49733

39. Herdman M, Fox-Rushby J, Badia X. A model of equivalence in the cultural adaptation of HRQoL instruments: the universalist approach. Qual Life Res. 1998;7(4):323-35. https://doi.org/10.1023/a:1024985930536

40. Soárez PC, Castelo A, Abrão P. Holmes WC, Ciconelli RM. Tradução e validação de um questionário de avaliação de qualidade de vida em AIDS no Brasil. Rev Panam Salud Publica. 2009;25(1):69-76.

41. Medeiros RKS, Ferreira Júnior MA, Pinto DPSR, Vitor AF, Santos VEP, Barichello E. Modelo de validação de conteúdo de Pasquali nas pesquisas em enfermagem. Ref Rev Enferm. 2015;4(4):127-35. http://doi.org/10.12707/RIV14009

42. Vituri DW, Matsuda LM. Validação de conteúdo de indicadores de qualidade para avaliação do cuidado de enfermagem. Rev Esc Enferm USP. 2009;43(2):429-37. https://doi.org/10.1590/S0080-62342009000200024

43. Pedreira RBS, Rocha SV, Santos CA, Vasconcelos LRC, Reis MC. Validade de conteúdo do Instrumento de Avaliação da Saúde do Idoso. Einstein. 2016;14(2):158-77. https://doi.org/10.1590/S1679-45082016AO3455

44. Freire ILS, Santos FR, Nascimento ACS, Medeiros AB, Silva BCO, Cavalcanti CAA. Validação de questionário para avaliação do conhecimento de docentes e discentes de enfermagem sobre o suporte básico de vida. Rev Enferm UFPE Online. 2017;11(12):4953-60. https://doi.org/10.5205/1981-8963-v11i12a23556p4953-4960-2017

45. Pasquali L. Psicometria. Rev Esc Enferm USP. 2009;43 № esp:992-9. https://doi.org/10.1590/S0080-62342009000500002

46. World Health Organization; International Society for Prevention of Child Abuse and Neglect. Preventing child maltreatment: a guide to tanking action and generating evidence. Geneva $(\mathrm{CH})$ : WHO; 2006 [citado 19 jul 2020]. Disponível em: https://apps.who.int/iris/handle/10665/43499

47. Abreu CCNB. A infância vitimizada: retratos da violência doméstica contra a criança. Curitiba, PR: Appris; 2016.

Financiamento: Coordenação de Aperfeiçoamento de Pessoal de Nível Superior - Brasil (Capes) - Código de Financiamento 001 (FGP). Conselho Nacional de Desenvolvimento Científico e Tecnológico (CNPq) - Bolsa de Produtividade em Pesquisa 314218/2018-1 (MCV).

Contribuição dos Autores: FGP e MCV participaram de todas as etapas para a elaboração do artigo.

Conflito de Interesses: Os autores declaram não haver conflito de interesses. 